\title{
AVALIAÇÃO DAS CONDIÇÕES HIGIÊNICO SANITÁRIAS NA RECEPÇÃO E NO ARMAZENAMENTO DE ALIMENTOS: UM ESTUDO DAS CANTINAS SOLIDÁRIAS DA UEFS
}

\author{
Geisiane dos Santos Silva'; José Raimundo Oliveira Lima² \\ 1. Bolsista PIBIC/FAPESB, Graduanda em Engenharia de Alimentos, Universidade Estadual de Feira de Santana, e- \\ mail: geeise_santos@hotmail.com \\ 2. Orientador, Departamento de Ciências Sociais Aplicadas, Universidade Estadual de Feira de Santana, e-mail: \\ zeraimundo@uefs.br
}

PALAVRAS-CHAVE: Recepção e Armazenamento; Economia popular e solidária; Boas práticas.

\section{INTRODUÇÃO}

O pequeno comércio é uma das principais atividades realizadas dentre os grupos da economia popular e solidária, destacando-se principalmente a produção de alimentos e artesanato.

A economia solidária propõe alternativas de geração de trabalho e renda, e uma resposta a favor da inclusão social. Neste âmbito de inclusão, é organizada como uma diversidade de práticas econômicas e sociais que realizam atividades que tem como objetivo trabalho e renda para esses grupos comunitários (SINGER, 2008).

As incubadoras universitárias surgem a partir de uma conduta/ação diferente do que ocorre com a economia tradicional (estimula a competitividade e individualismo) dentro das universidades. O trabalho de incubação nas incubadoras é desenvolvido em um processo de orientação educativo-politico-pedagógico com grupos informais, que visa estreitar a relação da comunidade externa com a universidade (PITA et al., 2015).

Baseada nos princípios de relações solidárias, cooperação, autogestão, valorização dos produtos regionais e locais, a Incubadora de Iniciativas da Economia Popular e Solidária (IEPS- UEFS) vem desenvolvendo atividades de pesquisa e extensão e especificamente, atuando em dois espaços de alimentação no campus central da Universidade Estadual de Feira de Santana, localizados nas cantinas do módulo I e VII.

Segundo a Resolução da Diretoria Colegiada (RDC) 216/04 é estabelecido Boas Práticas para serviços de alimentação. Onde se deve garantir que todo estabelecimento mantenha qualidade higiênico sanitária durante toda cadeia produtiva e distribuição (BRASIL, 2004)

Neste contexto, problematiza-se: como trabalhar com grupos que, de regra, lidam com o obstáculo da formação escolar deficiente, da dificuldade de acesso à informação e da organização do trabalho baseado na autogestão e ainda proteger a saúde da população, garantindo a satisfação de todas as partes envolvidas? Responder a essa indagação não é tarefa fácil, entretanto, pretende-se a partir do caminho indicado pelo processo de incubação de iniciativas de economia popular e solidaria avaliar esse trabalho nas Cantinas Solidárias da UEFS.

Com efeito, o objetivo desse trabalho consistiu na avaliação na recepção e armazenamento da matéria prima nos espaços das cantinas solidárias considerando as peculiaridades do trabalho desenvolvido no âmbito da Economia Popular e Solidária e, em especial, as dificuldades enfrentadas por grupos que de regra lidam com o obstáculo da formação escolar deficiente, da dificuldade de acesso à informação e da organização 
do trabalho baseado na autogestão e ainda proteger a saúde da população, garantindo a satisfação de todas as partes envolvidas.

\section{METODOLOGIA}

Para realização e desenvolvimento deste plano, foi realizado o acompanhamento da rotina dos grupos das Cantinas Solidárias da UEFS bem como avaliação de documentos e relatórios fornecidos pelos responsáveis que acompanham o local, a Pró Reitoria de Políticas Afirmativas e Assuntos Estudantis - Núcleo de Alimentação do Campus (PROPAAE-NAC) e outras pessoas que poderiam influenciar direta ou indiretamente no desenvolvimento do estudo (orientadores, consumidores e parceiros nos grupos de estudos)

Utilizando a metodologia da Pesquisa Participante, que é uma das formas adotadas pela IEPS /UEFS, que de acordo com Brandão (2006), pesquisadores e pesquisados participam através de todo o processo de investigação-educação-ação de forma articulada em objetivos comuns. Desta forma estabeleceu-se, uma aproximação aos grupos e a comunidade em que vivem, para que pudesse diagnosticar e observar o grau de conhecimento e aplicação sobre o tema proposto.

Inicialmente foi realizada a etapa revisão da literatura dentro da perspectiva de desenvolvimento local, boas práticas para serviço de alimentação e assuntos relacionados, baseados na Resolução RDC $n^{\circ}$ 216, de 15 de setembro de 2004, que dispõe sobre Regulamento Técnico de Boas Práticas para Serviços de Alimentação.

Posteriormente foi realizada a etapa de planejamento de ações e assim a etapa exploratória para levantamento de dados como de conhecimento da rotina, o material que dispõem e condições de trabalho, bem como visitas as comunidades para levantamento de informações complementares através da observação in locus e entrevista aberta conforme Souza (2009) sobre a produção de insumos para alimentação sempre integrando de forma dialógica numa perspectiva de ação-reflexão-ação conforme Thiolent (1986).

\section{RESULTADOS E DISCUSSÃO}

A comercialização de alimentos da comunidade evidencia o desenvolvimento local, na medida em que os agricultores principais responsáveis pelo crescimento dessa pratica, e então, são visivelmente envolvidos no processo de produção de alimentos. Desta forma, é de suma importância à avaliação dos procedimentos denominados Boas Práticas de Fabricação em toda cadeia produtiva, desde a aquisição até a chegada do produto no consumidor. Assim, realizar o levantamento sobre a aquisição da matéria prima se faz útil, para garantir a produção segura dos alimentos, na medida em que se conhece e se evidencia todo processo, além de estimular o envolvimento orgânico local. Baseado nos conceitos inerentes a esse processo foi realizada a pesquisa através de instrumentos como entrevistas, observação dos hábitos dos envolvidos. Inicialmente a pesquisa, foi realizada na comunidade Distrito de Maria Quitéria - Feira de Santana, origem do grupo que atualmente ocupa a cantina do módulo I, visto que parte do fornecimento da matéria prima é originária de tal localidade produzidas sobre os princípios e praticas da Economia Popular e Solidária, conforme observamos nas discussões de Singer (2009) localidade. A pesquisa, de maneira geral, constituiu-se, os seguintes questionamentos: quais os principais alimentos fornecidos? E como esses alimentos são transportados até o destino final? Tratando-se de produção de alimentos, a qualidade do produto começa com o uso de matérias-primas de boa procedência, caracterizando um ponto de avaliação indispensável para a garantia da qualidade dos alimentos. As referências 
trabalhadas e aqui mencionadas, independente, das especificidades dão conta de forma adequada das discussões desses questionamentos.

De acordo com a pesquisa, os principais alimentos fornecidos são frutas regionais (umbu, cajá, caju, manga, acerola, laranja, banana) que de acordo com o seu período de safra aumenta em determinadas épocas do ano, aipim e seus derivados, bem como outros itens alimentares como farinhas, bolachas, sequilhos, galinha caipira, ovos, milho entre outros ampliam o leque de insumos alimentares. Observando-se que grande parte dos produtos são alimentos de maior perecibilidade, cuja diretrizes se observam mencionadas na (RDC) 216/04. Desta forma a preocupação surge a cerca da garantia da integridade e a qualidade da matéria prima, a fim de impedir sua contaminação e deterioração considerando que a aquisição é a primeira etapa do processo de produção torna-se possível identificar, entretanto, possíveis formas de contaminação (química, física, ou microbiológica), garantindo assim a qualidade etapas posteriores ao processo de fabricação.

Com base nessas informações e dados obtidos a etapa exploratória e de melhor sistematização foi realizada nos espaços do campus da universidade, foi utilizado como instrumento um modelo da lista de verificação de compras e máquina fotográfica. $\mathrm{O}$ objetivo principal da lista de verificação foi analisar a quantidade, e as formas de armazenamento da matéria prima no espaço. O período de coleta de dados compreendeu entre fevereiro a junho 2017. Tudo isso observado nas diretrizes das oficinas de BPF relidas conforme a (RDC) 216/04.

Segundo Oliveira (2016), as compras abrangem dois aspectos importantes que são os fornecedores/transporte e a administração de estoque de matérias-primas, ingredientes e embalagens. Destaca-se ainda a necessidade de realização das compras conforme a demanda de produção e por ausência no estoque, garantindo integridade dos insumos dentro de condições adequadas de armazenamento e conservação buscando a qualidade em todo processo. Verificou-se que o espaço não comporta grandes quantidades de matéria prima, devido o padrão de estrutura dos espaços, entretanto o grupo tenta dinamizar as compras em dias alternados para garantir o controle do estoque.

Quanto à forma de armazenamento dos alimentos, verifica-se o cuidado em identificar os produtos e armazená-los em locais que consideram adequados (Figura 1). Porém, ainda é uma atividade que necessita de muita atenção e ser trabalhado, pois se trata de cuidados de acordo com a legislação e normas técnicas, para validar os produtos após aberto, o que difere da validade proposta pelo fabricante, por esse motivo ainda ocorre confusão com esses dados.

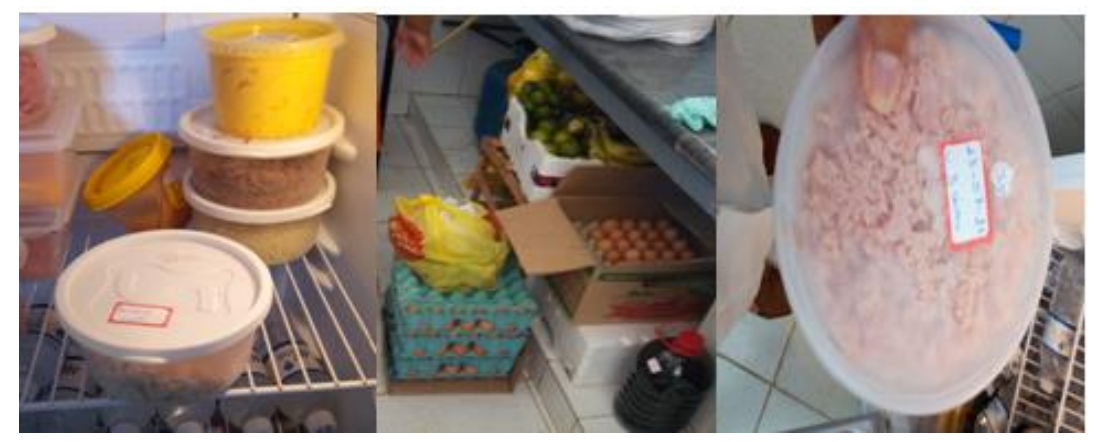

Figura 1: Registros durante a visita na cantina, maio/2017.

Diante dessa necessidade estudada de acordo com a legislação, e a partir da lista de compras e observações diárias, foi criada uma lista com o prazo de validade para 
produtos adquiridos em outro fornecedor, fracionados, preparados no local, e previamente cozidos juntamente com a Pró Reitoria de Políticas Afirmativas e Assuntos Estudantis- Núcleo de Alimentação do Campus (PROPAAE-NAC, UEFS.) que é o setor responsável por acompanhar os espaços que fornecem alimentos dentro da universidade.

\section{CONSIDERAÇÕES FINAIS}

Diante de uma comunidade (universitária) cada vez mais preocupada e exigente, a busca pela qualidade e segurança dos alimentos produzidos, é primordial e também visível nesta pesquisa. Sendo assim uma das formas para garantir a segurança do alimento é preocupar-se com toda a cadeia produtiva identificando potenciais perigos desde a aquisição da matéria prima (insumos) até a distribuição do produto final e envolver nesta preocupação a comunidade fornecedora também.

Neste contexto, a qualidade do produto começa com o uso de matérias-primas de boa procedência, tornando-se um ponto de avaliação indispensável para a garantia da qualidade dos alimentos produzidos pelas cantinas dentro da Instituição, inferência que se faz a partir desse processo de pesquisa.

A realização da avaliação do fornecimento e condições de armazenamento da matéria prima nos espaços das cantinas solidárias é essencial, considerando que se tratando de grupos de agricultura familiar e grande parte dos produtos são alimentos de maior perecibilidade, além disso, considerando as peculiaridades do trabalho desenvolvido e as dificuldades de acesso à informação e da organização do trabalho baseado na autogestão, o presente trabalho foi realizado de forma discutir possibilidades como forma de contribuição nas ações de formação realizadas pela IEPS, e garantir a informação à comunidade universitária sobre sua relação com os princípios da economia popular e solidária e a preocupação do processo de incubação dos grupos que ocupam as cantinas.

\section{REFERÊNCIAS}

BRANDÃO, C. R.(2006). O que é educação popular. São Paulo: Brasiliense

BRASIL. Ministério da Saúde. Agência Nacional de Vigilância Sanitária. Resolução $R D C n^{\circ} 216$, de 15 de setembro de 2004. Regulamentos Técnicos sobre de Boas Práticas para Serviços de Alimentação. Disponível em: <http:ttp://portal.anvisa.gov.br/wps/wcm/connect/4a3b680040bf8cdd8e5dbf1b0133649 b/RESOLU\%C3\%87\%C3\%83ODC+N+216+DE+15+DE+SETEMBRO+DE+2004.pdf ?MOD=AJPERES $>$. Acesso em 22 jul 2017.

IEPS, UEFS. Projeto Incubadora Tecnológica de Cooperativas Populares da Universidade Estadual de Feira de Santana. Feira de Santana.

OLIVEIRA, M. S. Gestão setorial: compras e recebimento.2016. Disponível em: http://www2.anhembi.br/html/ead01/gestao_fin_controladoria/aula3.pdf. Acesso em 19 jul 2017.

PITA, F.; LIMA, J. R. O; LIMA, C. E. S. Normatizando solidariedade: experiência de construção coletiva de regras de uma cooperativa informal de Economia Solidária. Outra Economia, v.9, 2015, p.69.

PROPAAE-NAC, UEFS. Pró reitoria de Políticas afirmativas e Assuntos EstudantisNúcleo de alimentação do campus. Relatórios de inspeção. Feira de Santana.

SINGER, P. I. Globalização e Desemprego: diagnósticos e alternativas. $7^{\circ}$ ed. São Paulo: Contexto, 2008.

SOUZA, M. M. O., A utilização de metodologias de diagnóstico e planejamento participativo em assentamentos rurais: o diagnóstico rural/rápido participativo (DRP). EM EXTENSÃO, Uberlândia, v. 8, n. 1, p. 34 - 47, jan./jul. 2009.

THIOLLENT, Michel. Metodologia da pesquisa-ação. São Paulo: Cortez,1986. 